\title{
Impact of magnetic storms on the global TEC distribution
}

\author{
Donat V. Blagoveshchensky ${ }^{1}$, Olga A. Maltseva ${ }^{2}$, and Maria A. Sergeeva ${ }^{3,4}$ \\ ${ }^{1}$ Saint-Petersburg State University of Aerospace Instrumentation, 67, Bolshaya Morskaya, Saint Petersburg, 190000, Russia \\ ${ }^{2}$ Institute for Physics, Southern Federal University, Stachki, 194, Rostov-on-Don, 344090, Russia \\ ${ }^{3}$ SCiESMEX, LANCE, Instituto de Geofisica, Unidad Michoacan, Universidad Nacional Autonoma de Mexico, \\ Morelia, 58089, Mexico \\ ${ }^{4}$ CONACYT, Instituto de Geofisica, Unidad Michoacan, Universidad Nacional Autonoma de Mexico, \\ Morelia, 58089, Mexico
}

Correspondence: Maria A. Sergeeva (maria.a.sergeeva@gmail.com)

Received: 7 January 2018 - Discussion started: 16 January 2018

Accepted: 22 May 2018 - Published: 2 August 2018

\begin{abstract}
The study is focused on the analysis of total electron content (TEC) variations during six geomagnetic storms of different intensity: from $\mathrm{Dst}_{\min }=-46 \mathrm{nT}$ to $\mathrm{Dst}_{\min }=$ $-223 \mathrm{nT}$. The values of TEC deviations from its 27 -day median value ( $\delta$ TEC) were calculated during the periods of the storms along three meridians: American, Euro-African and Asian-Australian. The following results were obtained. For the majority of the storms almost simultaneous occurrence of $\delta$ TEC maximums was observed along all three meridians at the beginning of the storm. The transition from a weak storm to a superstorm (the increase of magnetic activity) almost does not affect the intensity of the $\delta$ TEC maximum. The seasonal effect was most pronounced along the Asian-Australian meridian, less often along the Euro-African meridian and was not revealed along the American meridian. Sometimes the seasonal effect can penetrate to the opposite hemisphere. The character of average $\delta$ TEC variations for the intense storms was confirmed by GOES satellite data. Though there are some common features of TEC variation revealed during each storm phase, in general no clear dependence of TEC responses on the storm phases was found: the effects were different during each storm at different locations. The behavior of the correlation coefficient $(R)$ between $\delta$ TEC values along the three meridians was analyzed for each storm. In general, $R>0.5$ between $\delta$ TEC values averaged along each meridian. This result is new. The possible reasons for the exceptions (when $R<0.5$ ) were provided: the complexity of phenomena during the intense storms and discordance in local time of the geomagnetic storm beginning along different meridians. Notwithstanding the complex dependence of $R$ on
\end{abstract}

the intensity of magnetic disturbance, in general $R$ decreased with the growth of storm intensity.

\section{Introduction}

The changes in the Earth's geomagnetic field provoked by space weather events can cause ionospheric disturbances. These are very complex phenomena. One of the parameters that help to estimate the ionosphere state change is the vertical total electron content (TEC) which is the quantity of electrons in a column of unit cross section (Davies and Hartmann, 1997; Afraimovich and Perevalova, 2006). Usually, TEC is calculated using phase and code delays of GNSS satellites signals received by dual-frequency ground receivers. The ionosphere is represented by a thin shell of zero thickness at the altitudes of the ionospheric $\mathrm{F}$ region when calculating TEC (Schaer et al., 1995; Komjathy, 1997). Though TEC is an integral characteristic (electron content from the satellite to the ground), it is assumed that it characterizes the state of the $\mathrm{F}$ region of the ionosphere. This is due to the fact that the main contribution to electron content is provided by the ionospheric $\mathrm{F}$ region. In recent years, TEC has been widely used for ionosphere diagnostics for local regions and on a global scale due to the availability of signals in all-time, allweather conditions around the globe (Panda et al., 2015) and the large coverage of GNSS receivers worldwide in comparison to other ground-based instruments, such as ionosonde networks and radars. Despite a large number of publications dedicated to the disturbed ionospheric state, new data are 
still interesting to analyze. In the majority of studies, data of vertical ionospheric sounding and TEC are used together. However, at present, TEC acts as an independent parameter, in particular to estimate disturbances as, for example, in the works of Jakowski et al. (2006) and Gulyaeva and Stanislawska (2008).

The choice of events for the analysis usually varies from several storms, for instance 15 cases during 2006-2007 (Cander and Ciraolo, 2010) or 217 events between 2001 and 2015 (Liu et al., 2017), to the detailed studies of a particular event, as in Astafyeva et al. (2015). In the present work we study the global ionospheric responses to six geomagnetic storms using TEC data. The storms of different intensity (from weak to severe) were chosen within a short time interval (1-year period). The effects of the storms of different intensity on the ionosphere were compared.

A number of works have addressed global ionosphere variations during disturbances. One of the possible approaches is to study the behavior of parameters along different meridians (Mansilla, 2011; Astafyeva et al., 2015). The majority of studies on the latitudinal or longitudinal dependences of ionospheric responses are limited to a particular latitudelongitude region, although there are studies on global density distributions. For example, Zhao et al. (2007) suggested the presence of a longitudinal effect of the ionospheric storm caused by a geomagnetic disturbance. Using global ionospheric maps (GIMs) Rajesh et al. (2016) showed that midlatitude electron density enhancements exhibit significant longitudinal dependence. Longitudinal varieties of the ion total density in the equatorial and middle-low latitudinal topside ionosphere at four local times were studied by Chen et al. (2015). Latitudinal variations between longitudes 40 and $100^{\circ} \mathrm{E}$ in the Indian zone were addressed by Bhuyan et al. (2003). Nogueira et al. (2013) examined the four-peaked structure in the observed topside ion density and its manifestation as longitudinal structures in TEC over South America. Dmitriev et al. (2013) performed the longitudinal analysis of the dayside ionospheric storms within the region of the equatorial ionization anomaly during recurrent geomagnetic storms. Longitudinal features of electron density distributions were studied in Klimenko et al. (2016a, b) for minimum solar activity using modeling, GPS and satellite observations.

The present study addresses the global longitudinal TEC features not limited by one particular latitude-longitude zone. Three longitude sectors rather far from each other were chosen for the analysis: along the American meridian $\left(100^{\circ} \mathrm{W}\right)$, along the Euro-African meridian $\left(15^{\circ} \mathrm{E}\right)$ and along the Asian-Australian meridian $\left(115^{\circ} \mathrm{E}\right)$. The effects were studied along these three longitudes within the latitude interval between $60^{\circ} \mathrm{N}$ and $60^{\circ} \mathrm{S}$.

The storms considered in the present study were also the subject of several case studies, mostly for some particular region. For example, Polekh et al. (2016) addressed the event of 17 March 2015, Astafyeva et al. (2016) studied the iono- sphere during 22 June 2015 and Chashei et al. (2016) considered ionospheric effects during the storm on 20 December 2015. In our case the focus is on global effects.

The aim of this work was to reveal the features of TEC variations during the particular geomagnetic storms along three meridians: American, Euro-African and AsianAustralian. The tasks were to (1) obtain TEC variations along each meridian, (2) find if there is any correlation between these variations and (3) reveal if there are any distinctive characteristics of TEC behavior during the considered storms and how these characteristics depend on the intensity of the disturbance and are connected to the meridian itself.

\section{Data used for the analysis}

\subsection{Parameters of magnetic storms}

Six geomagnetic storms within a 1-year interval between March 2015 and March 2016 were chosen for the analysis. This period coincides with the descending phase of the solar activity cycle, not far from its maximum which occurred in 2014. The majority of the storms occurred during the wintertime in the Northern Hemisphere (if March is categorized as a winter month) and summertime in the Southern Hemisphere. We have chosen storms of different intensity. Figure 1a illustrates the Dst (disturbance storm time) index variations characterizing the disturbances. Vertical lines indicate the main phase (MP), the recovery phase (RP) and the end of the storm (Te). In some cases sudden storm commencements (SSCs) are also indicated.

Table 1 provides information about each event under analysis. The number assigned to each storm is given in the first column. The same numbers are used to label the panels of Fig. 1 (between the left and right columns). The dates of disturbances are given in the second column of Table 1. The time moments of the beginning of the main phase of the storm are given in the third column. Minimal Dst index values are given in the fourth column. The fifth column shows SYM-H index minimum values to provide the full picture of the disturbance. The sixth column shows the time of the beginning of the recovery phase of each storm. The seventh column presents the time moments of the end of the storm (Te). Here, "e" means end. Main and recovery phases were defined based on Dst variation. The Te moment corresponded to the end of the storm when the Dst value was about $(-10 /-15) \mathrm{nT}$ or before the next SSC. The geomagnetic storms are presented in Table 1 from the less intense (first line) to the most intense (sixth line) according to the Dst index. Gonzalez et al. (1994) introduced a storm classification as follows: intense storms are characterized by Dst $\leq-100 \mathrm{nT}$, moderate storms by $-100 \mathrm{nT} \leq \mathrm{Dst} \leq-50 \mathrm{nT}$ and weak storms by $-50 \mathrm{nT} \leq \mathrm{Dst} \leq-30 \mathrm{nT}$. According to this classification, storm no. 1 (14 December 2015) is weak, storm no. 2 (6 March 2016) is moderate and storms no. 3, 4, 5 
(a)
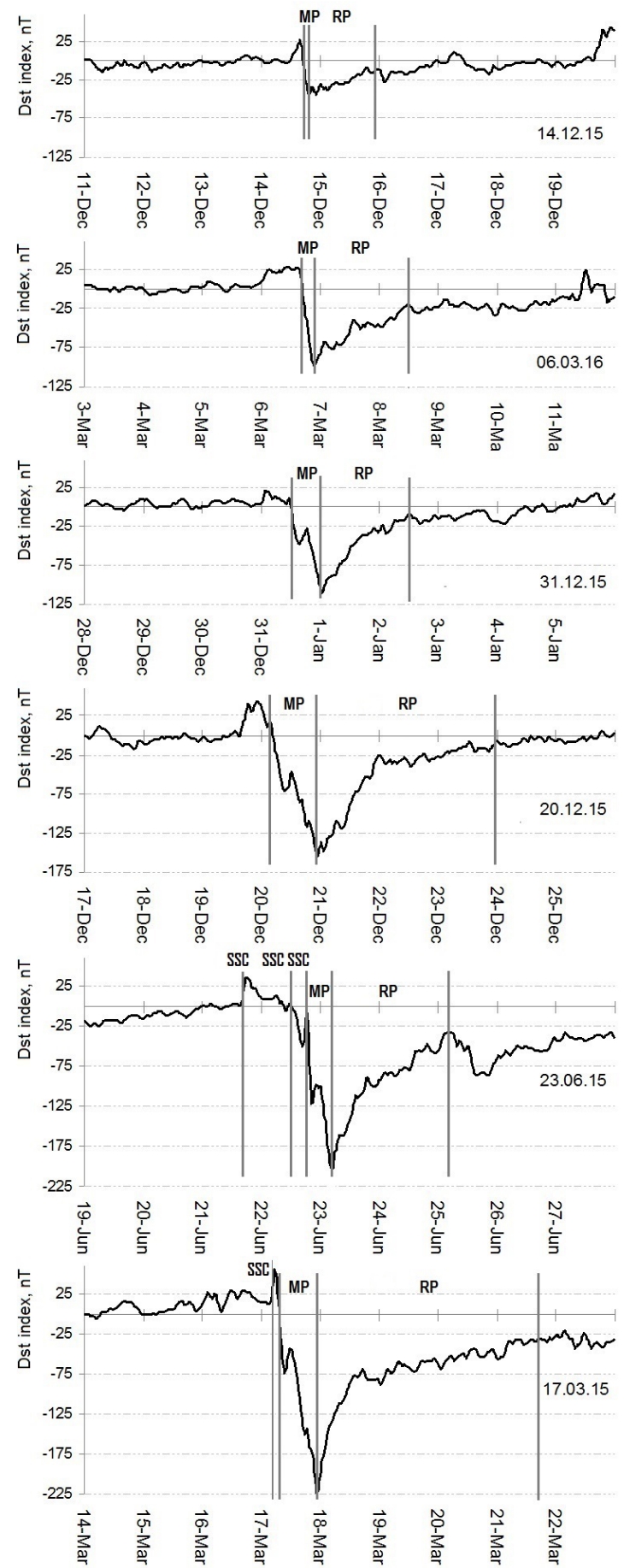

(b)

(1)

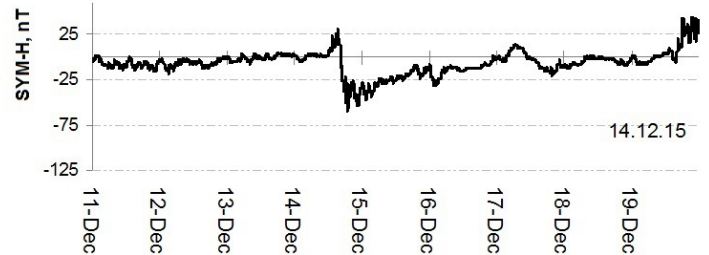

(2)

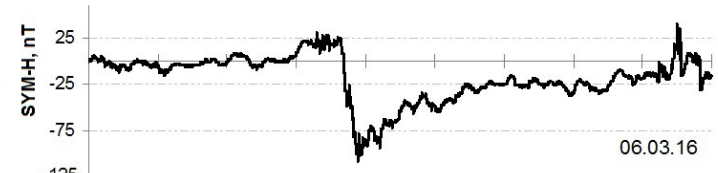

(3)
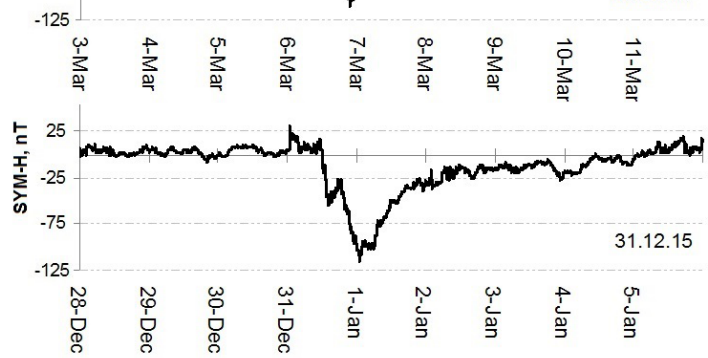

(4)
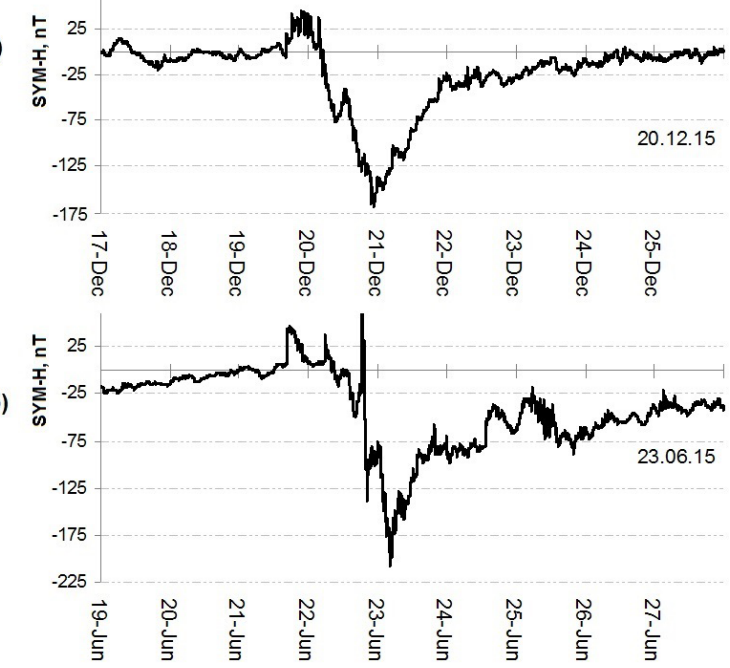

(6)

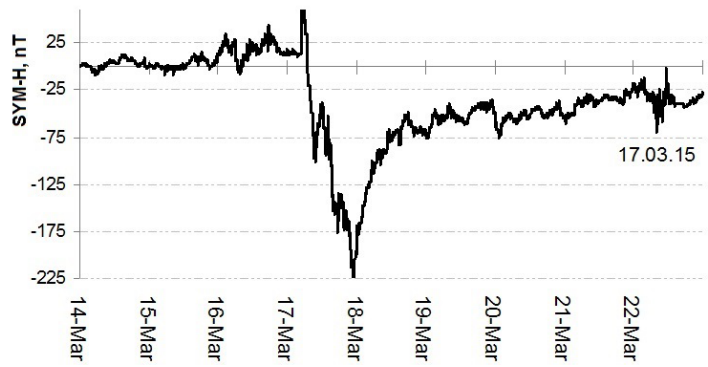

Figure 1. Dst index (a) and SYM-H index (b) variations during the periods of six geomagnetic storms under analysis. Main (MP) and recovery phases (RP) as well as sudden storm commencements (SSCs) are marked by vertical lines based on Dst index variation.

and 6 are intense. The last storm (17 March 2015) is called a superstorm in literature because it was the most intense storm of the solar cycle 24 . Thus, all six considered storms are of different intensities.

\section{$2.2 \quad$ TEC data}

TEC values were obtained from GIMs produced by the International GNSS Service (IGS). GIMs of TEC are inde- 
Table 1. Characteristics of the geomagnetic storms used in the analysis.

\begin{tabular}{|c|c|c|c|c|c|c|}
\hline No. & $\begin{array}{l}\text { Date of storm } \\
\text { beginning }\end{array}$ & $\begin{array}{l}\text { Beginning of the main phase } \\
\text { (based on the Dst index) }\end{array}$ & $\begin{array}{l}\text { Minimum value } \\
\text { of the Dst index }\end{array}$ & $\begin{array}{r}\text { Minimum value } \\
\text { of the SYM-H index }\end{array}$ & $\begin{array}{l}\text { Beginning of the recovery } \\
\text { phase (based on the Dst index) }\end{array}$ & $\begin{array}{l}\text { Te (storm end based } \\
\text { on the Dst index) }\end{array}$ \\
\hline 1 & 14 Dec 2015 & 16:00 UT, 14 Dec 2015 & $-47 \mathrm{nT}$ & $-60 \mathrm{nT}$ & 19:00 UT, 14 Dec 2015 & 22:00 UT, 15 Dec 2015 \\
\hline 2 & 6 Mar 2016 & 16:00 UT, 6 Mar 2016 & $-98 \mathrm{nT}$ & $-110 \mathrm{nT}$ & 21:00 UT, 6 Mar 2016 & 12:00 UT, 8 Mar 2016 \\
\hline 3 & 31 Dec 2015 & 12:00 UT, 31 Dec 2015 & $-110 \mathrm{nT}$ & $-117 \mathrm{nT}$ & 00:00 UT, 1 Jan 2016 & 12:00 UT, 2 Jan 2016 \\
\hline 4 & 20 Dec 2015 & 03:00 UT, 20 Dec 2015 & $-155 \mathrm{nT}$ & $-170 \mathrm{nT}$ & 22:00 UT, 20 Dec 2015 & 23:00 UT, 23 Dec 2015 \\
\hline 5 & 22 Jun 2015 & 17:00 UT, 22 Jun 2015 & $-204 \mathrm{nT}$ & $-208 n T$ & 04:00 UT, 23 Jun 2015 & 05:00 UT, 25 Jun 2015 \\
\hline 6 & 17 Mar 2015 & 07:00 UT, 17 Mar 2015 & $-223 n T$ & $-234 \mathrm{nT}$ & 22:00 UT, 17 Mar 2015 & 17:00 UT, 21 Mar 2015 \\
\hline
\end{tabular}

pendently computed by four Analysis Centers of the International GPS Service for Geodynamics (CODE, JPL, UPS, ESA) and then ranked and combined according to the corresponding weight by the International GNSS Service to produce the IGS global vertical TEC maps (Hernandez-Pajares et al., 2009). These final IGS maps were used for this study. TEC values were extracted from IONEX files, freely available at ftp://cddis.gsfc.nasa.gov/pub/gps/products/ionex (last access: 5 January 2018). The GIM provides the spatial resolution of $5^{\circ}$ longitude and $2.5^{\circ}$ latitude worldwide; thus, it is a useful tool for ionosphere diagnostics on a global scale.

For each observation point, the median TEC value was calculated on the basis of 27 previous days for every $2 \mathrm{~h}$ of the day (universal time, UT). Thus, its own median value was obtained for each day every $2 \mathrm{~h}$. Furthermore, the deviation of TEC was calculated and plotted during each storm as well as 6 days before and 6 days after it following Eq. (1):

$\delta \mathrm{TEC}=\frac{(\mathrm{TECobs}-\mathrm{TECmed} 27)}{\mathrm{TECmed} 27} \times 100 \%$,

where TECobs is the observed value and TECmed 27 is a median value calculated for the 27 days prior to the day of observation.

\subsection{Satellite and geomagnetic data}

Data from GOES weather satellites that circle the Earth in a geosynchronous orbit were used in the analysis (https://satdat.ngdc.noaa.gov/sem/goes/; last access: 5 January 2018). The altitude of their orbit is about $35800 \mathrm{~km}$. GOES- 13 is positioned at $75^{\circ} \mathrm{W}$ longitude and over the equator, monitoring North and South America and the Atlantic Ocean. GOES- 15 is positioned at $135^{\circ} \mathrm{W}$ longitude and over equator, monitoring North America and the Pacific Ocean. The coverage by two satellites extends approximately from $20^{\circ} \mathrm{W}$ longitude to $165^{\circ} \mathrm{E}$ longitude. The instruments for near-Earth space weather monitoring are installed on board including a magnetometer, an X-ray sensor, a high-energy proton and alpha detector and an energetic particles sensor.

To estimate geomagnetic conditions, the Dst and SYM$\mathrm{H}$ indices values were used. Both indices are the indicators of global space weather effects. Data are freely available at http://wdc.kugi.kyoto-u.ac.jp (last access: 5 January 2018). Wanliss and Showalter (2006) showed that the SYM-H index can be used as a de facto high resolution of the Dst index as they are quite similar in their characterization of the storms of different intensity. This similarity is also seen in Fig. 1 (columns a and b). We used the Dst index to define main and recovery phases of the storms: (a) for illustrative purposes as the Dst curve is less rugged and (b) as we use classification of the intensity of the storms based on the Dst index (Sect. 2.1).

\section{Discussion of results}

\subsection{Specific features of TEC variations during the considered storms}

Variations of $\delta$ TEC were the main source of information on the changes in the ionosphere. According to these data, the bursts of $\delta$ TEC occurred at the beginning of the magnetic disturbance. The duration of these bursts varied within several hours. The behavior of $\delta$ TEC along American, Euro-African and Asian-Australian meridians was studied with $10^{\circ}$ steps in latitude from $60^{\circ} \mathrm{N}$ to $60^{\circ} \mathrm{S}$.

\subsubsection{Weak $\delta$ TEC variations}

Sometimes manifestations of the disturbance in TEC during geomagnetic storms were weak or absent within the latitude range of $\pm 20^{\circ}$ near the equator. Figure 2 provides the example of the storm of 31 December 2015 in the Euro-African sector. Here, to save space, the plots are shown with $20^{\circ}$ latitude steps along the longitude. Days in UT are given along the $x$ axis; additionally markings were made every $2 \mathrm{~h}$ (UT). To confirm this example a more detailed picture of TEC behavior is considered for the case of latitude $20^{\circ} \mathrm{N}$ from Fig. 2. Figure 3a shows the values of the observed TEC (TECobs, green curve), its 27-day running median (TECmed27, red dotted curve) and the standard deviation $\sigma$ of TECobs (blue curve). Main and recovery phases (MP, RP) and the end of the storm (Te) are marked by the vertical lines. Median values serve as a quiet reference. It is seen that TEC observed during 31 December 2015- 2 January 2016 (storm period) in general followed its quiet pattern (Fig. 3a). The maximal TEC deviation from its quiet state reached $-28 \%$. Such deviation can be referred to as day-to-day variability. In contrast, a different picture was observed for the same latitude $20^{\circ} \mathrm{N}$ but along the American meridian. Figure $3 \mathrm{~b}$ shows 


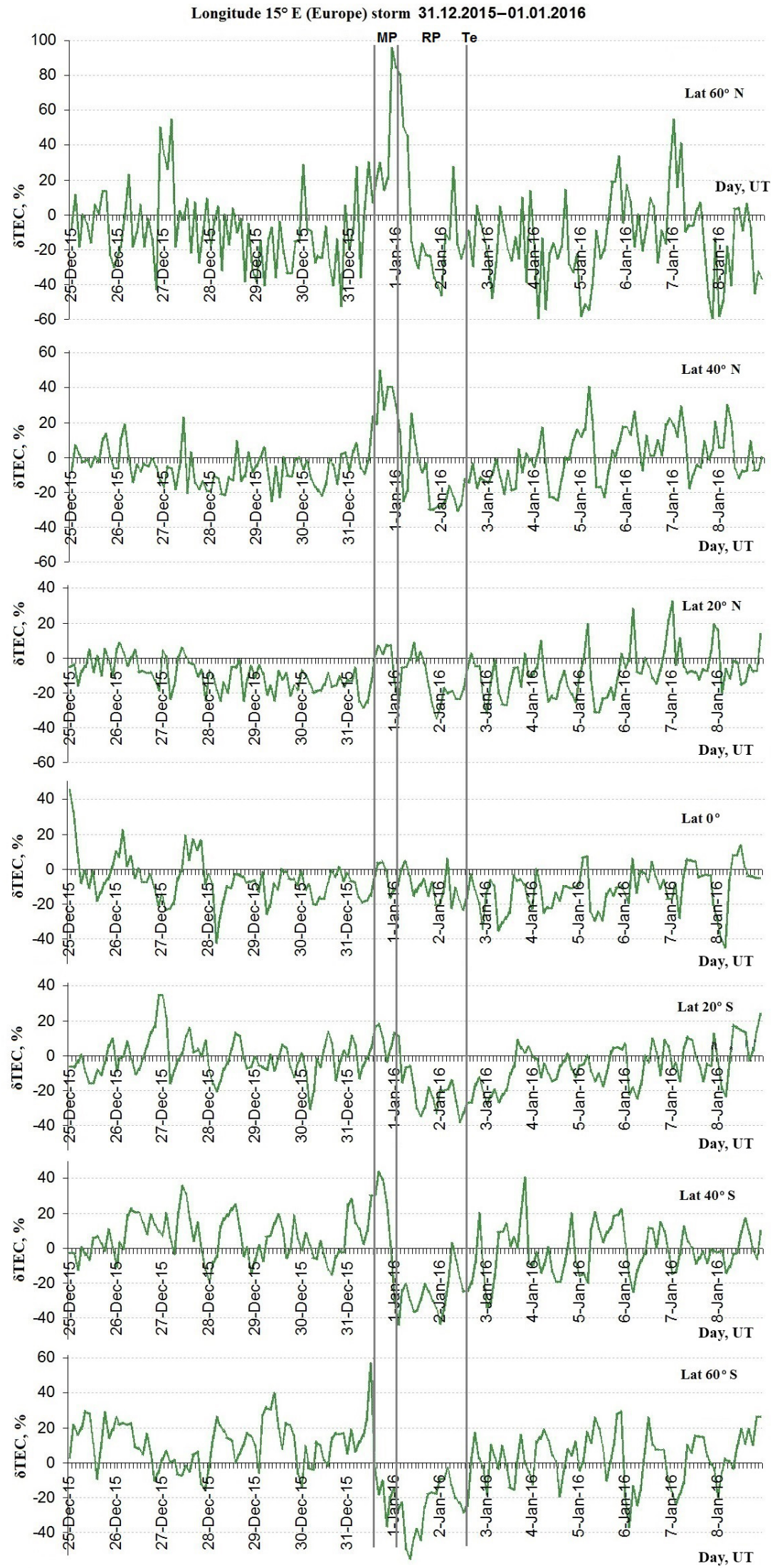

Figure 2. Weak manifestation of TEC effects within the latitudes $\pm 20^{\circ}$ during the storm of 31 December 2015. MP, RP and Te are marked by vertical lines. 


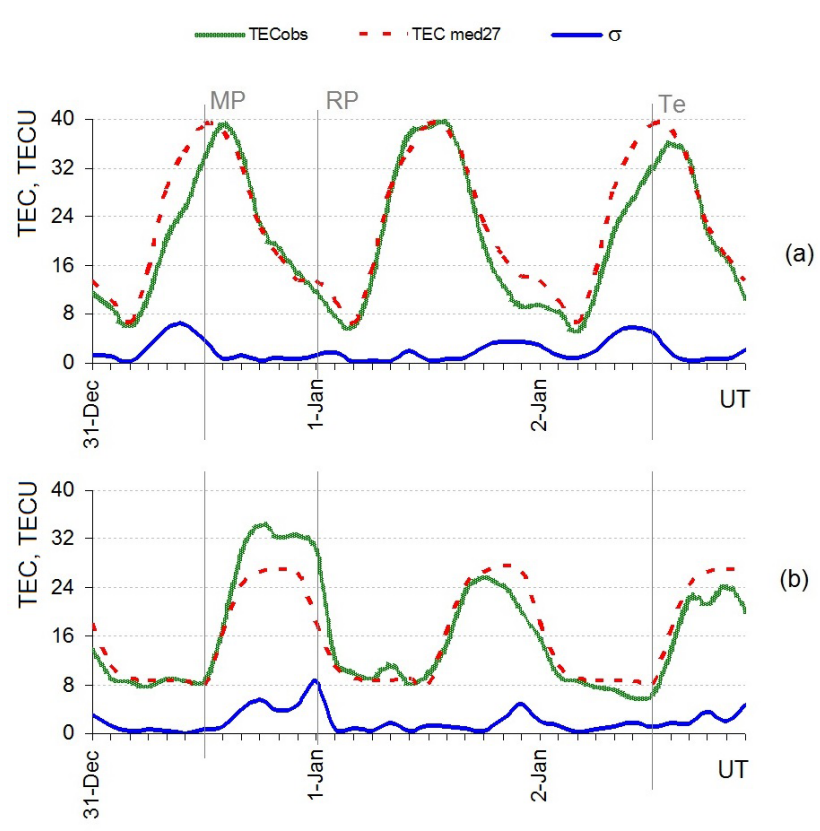

Figure 3. Results for storm no. 3 at latitude $20^{\circ} \mathrm{N}$ : for EuroAfrican (a) and American meridians (b). Observed TEC (green curve), 27-day running median (red dotted curve) and standard deviation $\sigma$ of the observed TEC (blue curve). MP, RP and Te are marked by vertical lines.

the results: the geomagnetic storm first caused the positive and then the negative TEC disturbance, with a maximal TEC change of $67 \%$ from its quiet state. This specific example proves the presence of weak (almost absent) TEC disturbances within the latitudes $\pm 20^{\circ}$ in the particular sector.

\subsubsection{Seasonal effect}

The presence of seasonal effects in $\delta$ TEC variations was revealed for the following cases.

(a) During storm no. 2 (6 March 2016) the positive phase of disturbance was the dominant effect in $\delta$ TEC variations during the night hours (UT) between 6 and 7 March along the Asian-Australian meridian from latitude $60^{\circ} \mathrm{N}$ to latitude $0^{\circ}$. In contrast, along the same meridian from 10 to $60^{\circ} \mathrm{S}$ the positive phase was followed by a negative phase. In other words, during this storm the positive disturbance covered the latitudes of the winter hemisphere; meanwhile the summer hemisphere was characterized by a positive disturbance followed by a negative disturbance.

(b) A similar picture was observed along the same (AsianAustralian) meridian during storm no. 4 (20 December 2015). However, though the general tendency of $\delta$ TEC was similar along the whole meridian (an increase of values followed by a decrease), in terms of phases the positive phase followed by a decrease of val- ues prevailed in the Northern (winter) Hemisphere from latitudes 60 to $30^{\circ} \mathrm{N}$ (Fig. 4a). Further, from $20^{\circ} \mathrm{N}$ to $60^{\circ} \mathrm{S}$, a $\delta$ TEC increase followed by a clear negative phase was observed. Here, the "summer" effect penetrated into the "winter" hemisphere.

(c) Also during storm no. 4, along the Euro-African meridian from 20 to 22 December (00:00 UT), the disturbance showed a positive-negative-positive sequence of phases from 60 to $10^{\circ} \mathrm{N}$. Here, the second positive phase was much more intense and the whole disturbance within the interval $30^{\circ} \mathrm{N}-0^{\circ}$ began earlier. The latitudes of the Southern Hemisphere $0^{\circ}-60^{\circ} \mathrm{S}$ were covered by the negative phase during 21 December, with the preceding positive phase almost disappearing.

(d) During storm no. 5 (23 June 2015) along the EuroAfrican meridian, the negative phase in the form of two bays was observed from $60^{\circ} \mathrm{N}$ to $0^{\circ}$ (Fig. $4 \mathrm{~b}$ ). From 10 to $60^{\circ} \mathrm{S}$ the disturbance had a more complex character and included two or more positive phases. At the same time along the Asian-Australian meridian a negative phase was observed between 60 and $20^{\circ} \mathrm{N}$ (Fig. 4c). Starting from $10^{\circ} \mathrm{N}$ a positive phase (sometimes various peaks) was followed by a negative phase. The positive phase was in the form of a very intense burst $\left(+180 \%\right.$ and more) at latitudes between 20 and $60^{\circ} \mathrm{S}$. In this case, the winter effect penetrated into the Northern Hemisphere from the Southern Hemisphere.

To sum up, according to our data (cases a-d), the seasonal effect consists in general dominance of a negative phase (decrease of TEC) in summer and a positive phase (increase of TEC) in winter. This conclusion is in accordance with the case study (Kil et al., 2003). In the present study the effect was observed mostly over the Asian-Australian sector and no seasonal effect was registered over the American sector. Kil et al. (2003) addressed the case of the magnetic storm of 20 July 2000, using GIMs and low-orbit satellite data. They revealed clear seasonal effects: a dominance of the negative ionospheric storm in the summer (northern) hemisphere and the pronounced positive ionospheric storm in the winter (southern) hemisphere. Kil et al. (2003) also found that the Northern Hemisphere "summer" negative phase penetrated into the Southern Hemisphere. Our results also prove the possibility of the penetration of the seasonal effect into the opposite hemisphere. However, in our case both examples (b) and (d) showed such penetration from the Southern to the Northern Hemisphere: summer effects and winter effects, respectively. Thus, we may conclude that it does not depend on the season itself or on the hemisphere.

The storm analyzed by Kil et al. (2003) was very intense $\left(\right.$ Dst $\left._{\min }=-300 \mathrm{nT}\right)$. Our examples prove that the seasonal effect can be observed during the magnetic disturbance of less intensity (but still intense): $-98 \mathrm{nT}$ (a), $-155 \mathrm{nT}$ (b and c) and $-204 \mathrm{nT}(\mathrm{d})$. 
(a) Storm no. 4

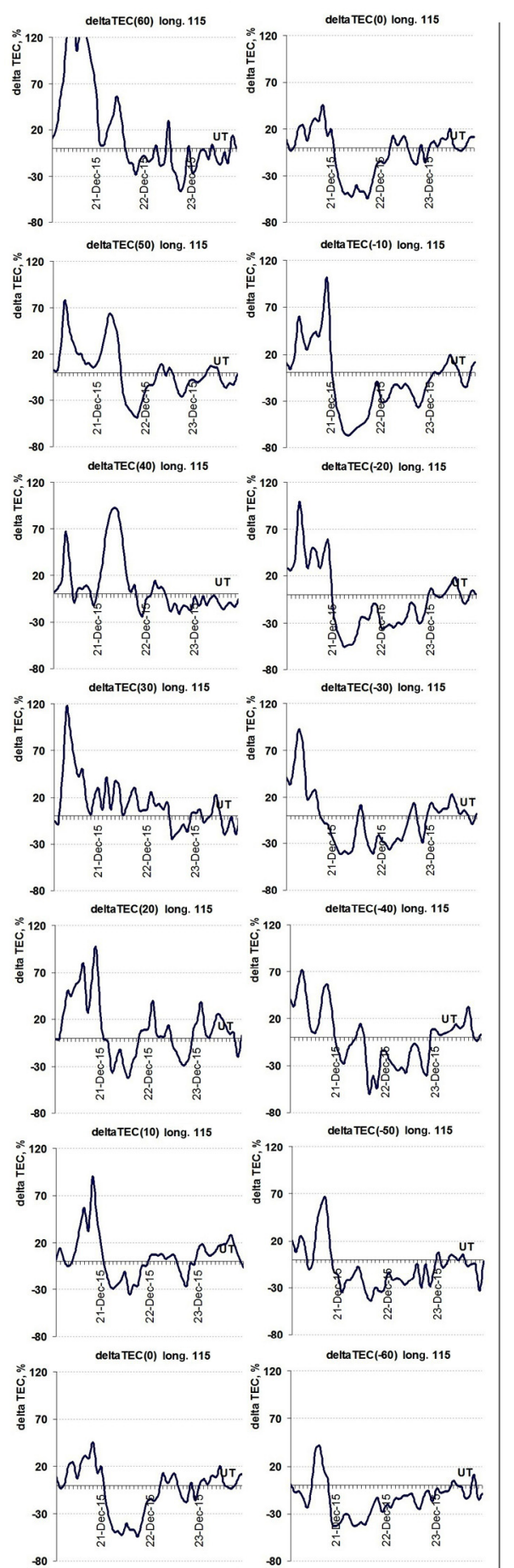

(b) Storm no. 5

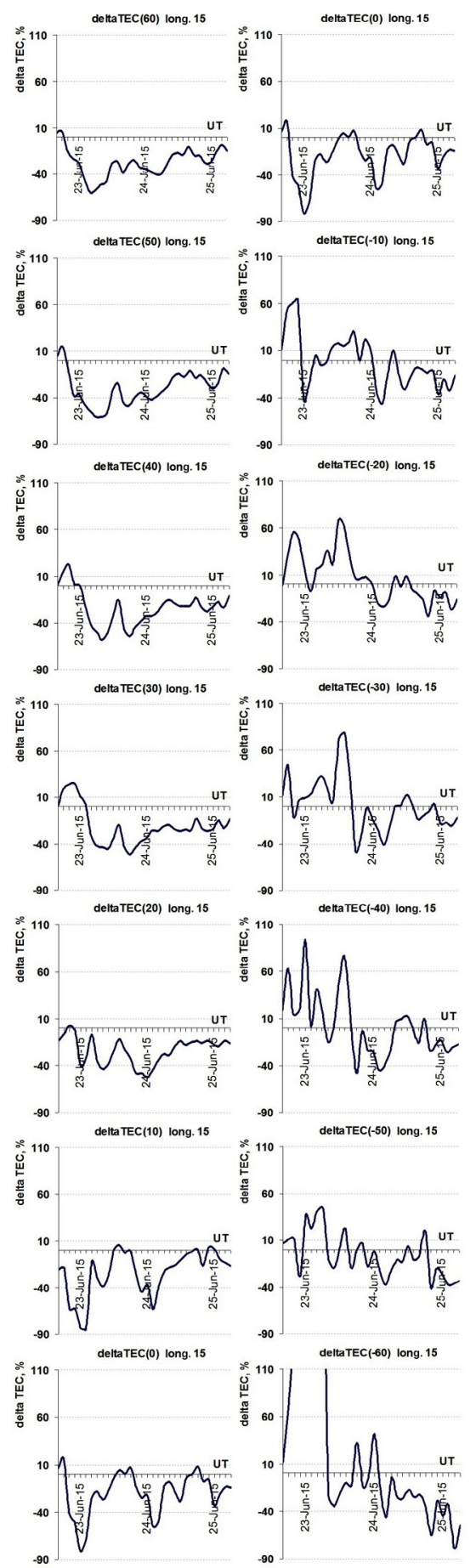

(c) Storm no. 5

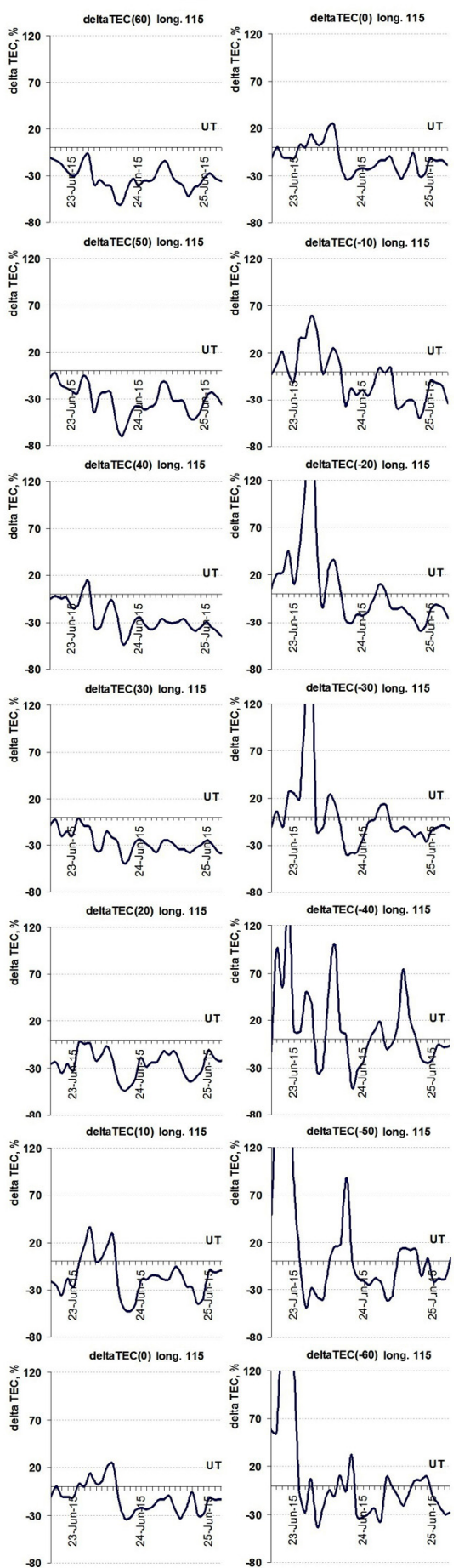

Figure 4. $\delta$ TEC variations for storms as follows: (a) no. 4 along the Asian-Australian meridian, (b) no. 5 along the Euro-African meridian and (c) no. 5 along the Asian-Australian meridian. The left-hand plots of columns a, b and c display variations in the Northern Hemisphere and the right-hand plots display variations in the Southern Hemispheres.

Here, we briefly mention that Zhao et al. (2007) also showed with GIMs of TEC that during magnetic disturbances a negative phase occurred with higher probability in the sum- mer hemisphere, while a positive phase occurred also with higher probability in the winter hemisphere. According to these authors, a negative phase was most prominent near ge- 
omagnetic poles and a positive phase was far from polar regions. According to our data within the latitudes $\pm 60^{\circ}$, a positive phase is very probable during the disturbances. At the same time it is not contradictory as each geomagnetic storm is a particular unique event.

To conclude, the seasonal effects had longitudinal dependence: they were observed mostly over the Asian-Australian sector, sometimes over the Euro-African sector and not at all over the American sector.

\subsubsection{Global picture of $\delta$ TEC variations along three meridians}

Figure 5 shows the average $\delta$ TEC behavior. Each panel (a-f) represents the results for the particular storm: from the weakest (panel a) to the strongest (panel f). Storm dates are indicated below the panels. The time interval on the $x$ axis is the interval between the storm beginning and $\mathrm{Te}$ (individual for each storm), according to Table 1. Each panel consists of three plots: the upper plot represents variations in the American sector, the middle plot variations in the Euro-African and the lower plot variations in the Asian-Australian sector. The curve on each plot represents $\delta$ TEC values averaged along one meridian over the latitudes $60^{\circ} \mathrm{N}-60^{\circ} \mathrm{S}$ with $10^{\circ}$ steps ( $\delta$ TECav). In other words, the final $\delta$ TECav curve represents the average of $13 \delta$ TEC values from different latitudes. This averaging is possible because according to our data the tendency of an increase or decrease of $\delta$ TEC was the same at different latitudes along one meridian in most cases (without regard to the phase). The specific cases are described above and also considered below.

First, it is seen that the maximal $\delta$ TECav occurs close to storm's main phase beginning. Physically, it is explained by the fact that usually the drastic increase of particle flows from the magnetosphere into the ionosphere occurs at the beginning of each storm, which, in turn, results in a TEC disturbance. It is known that during the development of a disturbance the critical frequencies of the ionosphere decrease to lower than their initial quiet level (Blagoveshchensky, 2011). The same behavior is observed in TEC: minimum of $\delta$ TECav values is observed after the increase of $\delta$ TECav, caused by the main phase of storm.

The main feature seen in panels (a), (b) and (e) is approximately the same time (UT) of $\delta$ TECav maximum occurrence at all the latitudes along three meridians. In regard to panels (c) and (d), their results were discussed above. In addition, the $\delta$ TECav maximum took place at the same time along the Asian-Australian and Euro-African meridians. For the American meridian the peaks are shifted in time and the peaks themselves are more diffused when compared with Asia and Europe. Let us consider a more detailed picture of each panel of Fig. 5.

Panel (a) has the shortest disturbance duration due to the weakness of the geomagnetic storm on 14 December 2015. This weak intensity is the reason for the slow ionospheric response and the particle precipitation occurring with a certain delay from the storm beginning. The moments of $\delta$ TEC maximums coincide along the three meridians. In panel (b) $\delta$ TECav maximums were well pronounced and coincided in time along the three meridians during the moderate storm on 6 March 2016. Panel (c) illustrates the results for the storm on 31 December 2015. The time of the $\delta$ TECav maximums' occurrence was only the same along the Asian-Australian and Euro-African meridians. Panel (d) illustrates a picture similar to panel (c), but for the storm on 20 December 2015. Panel (e) shows the results for the intense storm of 23 June 2015. It was the only storm among the six that occurred during the summer in the Northern Hemisphere and during the winter in the Southern Hemisphere. However, no specific details were revealed in comparison to other considered storms. Panel (f) shows the results for the superstorm of 17 March 2015. Though it is the most intense storm among the six, in general $\delta$ TECav variations do not differ from the other storms: the increase of $\delta$ TECav was followed by its decrease. However, the negative phase was more pronounced when compared with the weak positive phase.

To conclude, there is no dependence of $\delta$ TECav maximums along the three meridians on the intensity of magnetic activity. We recall that the intensity of storms grows from panel (a) to panel (f), but no increase in $\delta$ TECav variations is detected.

\subsubsection{Global picture of $\delta$ TEC response to main and recovery phases of the storms}

The ionospheric responses to geomagnetic storms at different observation points have their peculiarities due to the differences in local hours, wind systems, electrical fields and other local effects. In addition, geomagnetic storms in different regions can manifest themselves differently. For instance, the exact moments of the geomagnetic storm beginning and its intensity can vary. To estimate the global effects of storm phases at different latitudes along three meridians qualitatively, we applied some generalization. First, we used the Dst index as a global measure of geomagnetic field change. Furthermore, as it was mentioned above, the tendencies of TEC increase/decrease in most cases were similar at different latitudes along each meridian; thus we can consider the average effects along the meridians. With regard to the phase of TEC disturbance, the picture was similar along each meridian in one hemisphere and sometimes in both hemispheres along the whole meridian. The example of such a picture is given in Fig. 6.

The rapid main phase of storm no. 1 (Table 1) provoked a TEC increase (beginning of the positive TEC disturbance) during $3 \mathrm{~h}$ of its duration in both hemispheres along the three meridians. The only exception was the Euro-African meridian in the Southern Hemisphere: TEC was already augmented before the main phase (Fig. 6b). The maximum of TEC bursts at all latitudes and meridians occurred during 
(a)

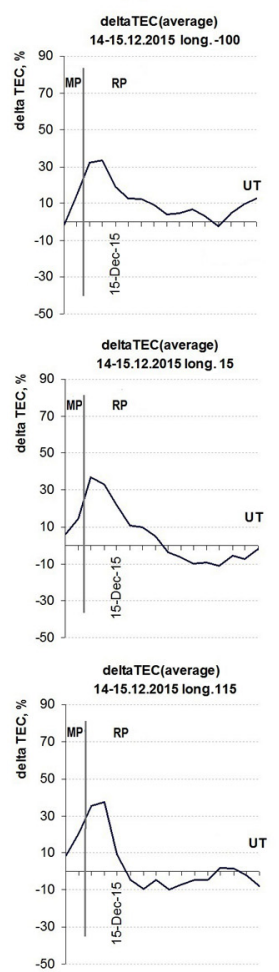

14.12.2015 (b)
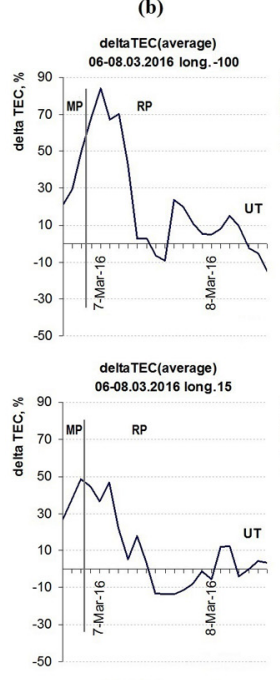

delta TEC(average)
$06-08.032016$ long. 115

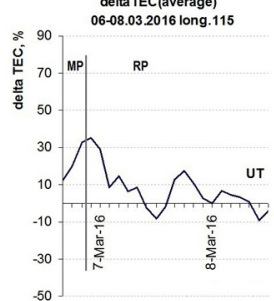

06.03.2016

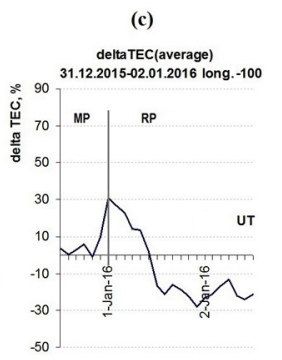

deltaTEC(average)
31.12.2015-02.01.2016 long. 15
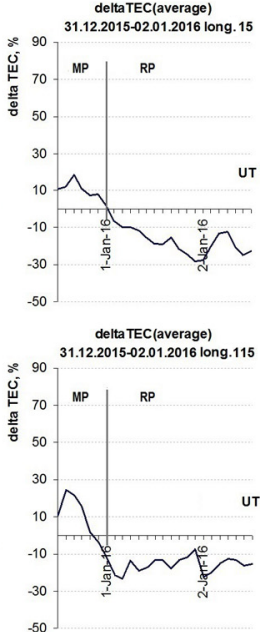

31.12.2015
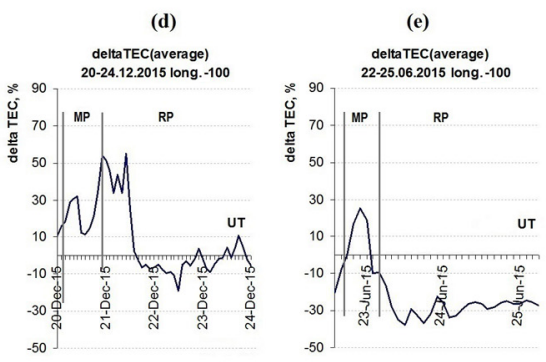

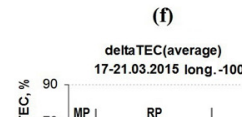

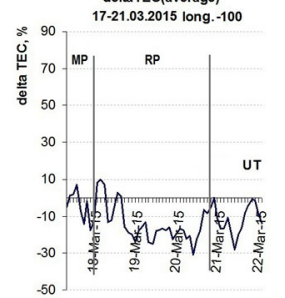

产

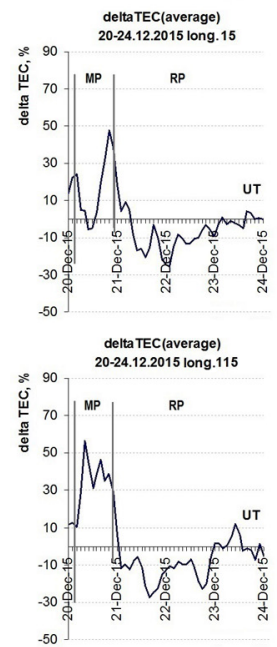

20.12.2015

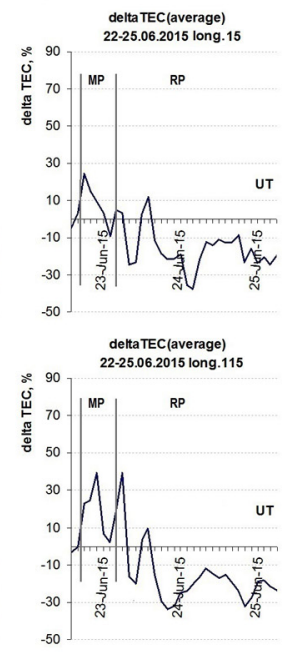

23.06.2015

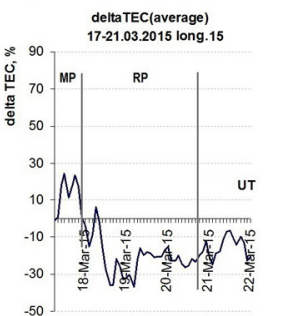

苛

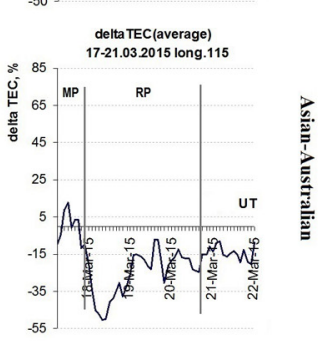

17.03.2015

Figure 5. $\delta$ TEC averaged along each meridian during the storms. Vertical lines indicate the periods of MP and RP.

the few hours after the beginning of the recovery phase. The negative phase followed TEC bursts during the second half of the recovery phase along the Euro-African and AsianAustralian meridians in the Southern Hemisphere. In the Northern Hemisphere and along the American meridian in the Southern Hemisphere TEC exhibited a second positive phase (less intense than the first maximum).

Storm no. 2 was characterized by a rapid Dst decrease (Fig. 1) and, consequently, by a short main phase ( $3 \mathrm{~h}$ as in the previous case). The recovery phase lasted $20 \mathrm{~h}$. As it is known the ionospheric response to a geomagnetic storm can occur immediately or with a delay of hours and even days. The latter is the case in our study. The effects in the ionosphere were observed during the recovery phase, probably because of the short duration of the main phase. In the Northern Hemisphere the positive TEC bursts occurred in the middle of the recovery phase along the whole of the American and Euro-African meridians as well as in the Southern Hemisphere along the Asian-Australian meridian with the subsequent decrease of TEC. In the Northern Hemisphere along the Asian-Australian meridian TEC showed more complex behavior and was mostly increased during the whole period of the storm.

The particular characteristics of storm no. 3 were already mentioned in Sect. 3.1.1 (weak $\delta$ TEC variations within $\pm 20^{\circ}$ ). Except this feature, in the Southern Hemisphere the main phase of the geomagnetic storm mostly caused a positive TEC disturbance and the recovery phase caused one or two negative TEC disturbances.

For storm no. 4, it can be assumed that the recovery phase provoked one or two negative phases of TEC disturbance along the Asian-Australian meridian. The effects in other sectors were too different to generalize them.

The case of storm no. 5 is more complicated as it developed in a background that was already disturbed: three SSCs provoked by the interplanetary shocks (Astafyeva et al., 2017) of different intensities occurred during the considered interval, at 16:46 UT on 21 June and at 05:47 and 18:30 UT on 22 June. An intense geomagnetic storm (storm no. 5) followed the last SSC with its main phase between 22 and 23 June (Fig. 1). In general, along the American, the southern part of the Euro-African and Asian-Australian meridians the positive TEC disturbance was observed during the main phase and the negative disturbance was observed during the recovery phase.

Superstorm no. 6 provoked complex effects at different observation points. Among the common features of TEC are the following. Along the American meridian the TEC burst was mostly caused during the main phase in the Northern Hemisphere and it was shifted towards the recovery phase in the 
(a)
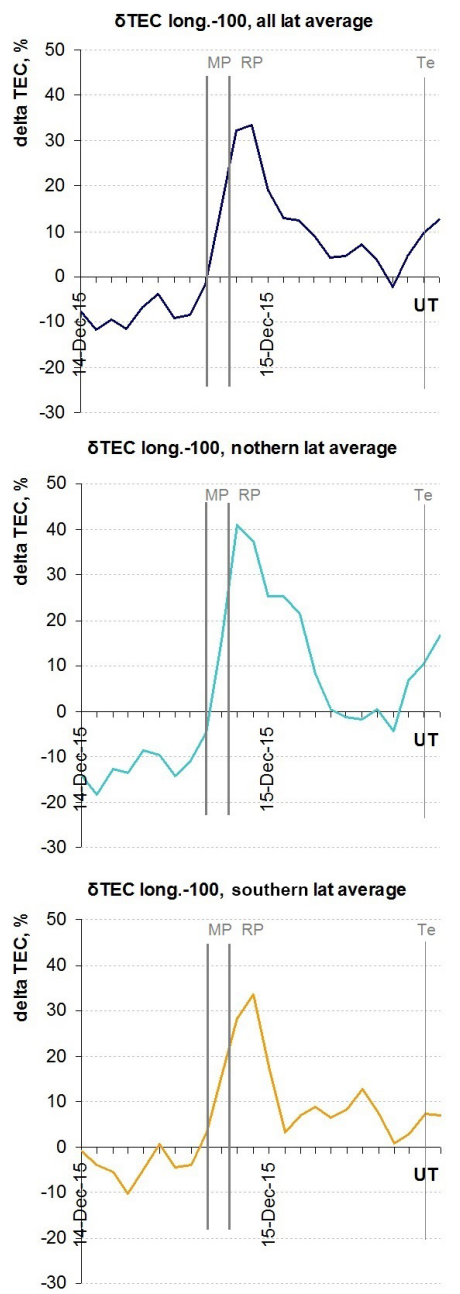

(b)

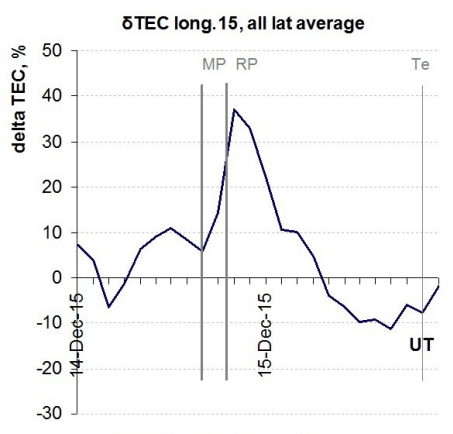

סTEC long. 15, nothern lat average

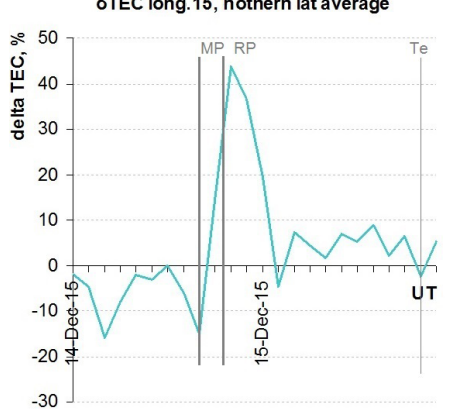

бTEC long.15, southern lat average

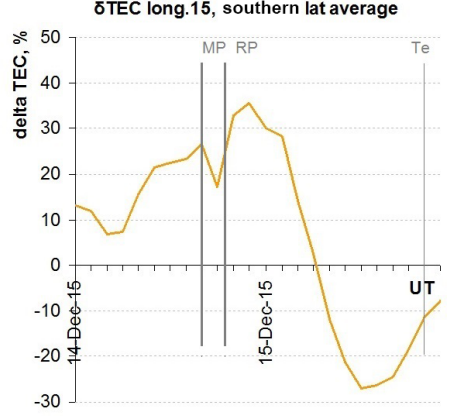

(c)
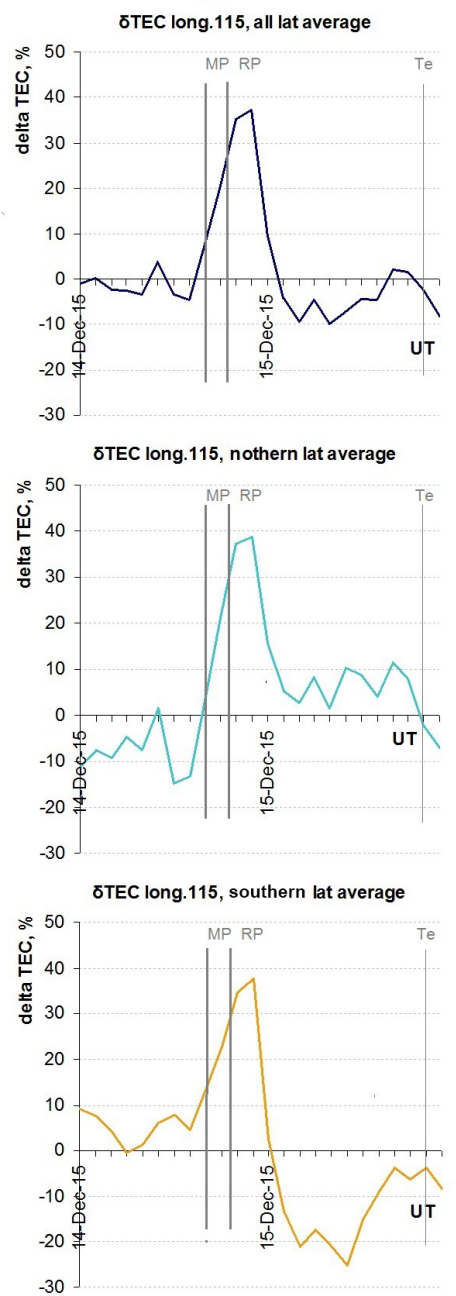

Figure 6. Results for storm no. 1: $\delta$ TEC averaged along the whole meridian (upper panels), along the Northern Hemisphere latitudes (middle panels) and along the Southern Hemisphere latitudes (lower panels) along the American (a), Euro-African (b) and Asian-Australian (c) meridians. MP and RP beginnings and Te are marked by vertical lines.

Southern Hemisphere. A TEC burst was observed during the main phase along the other two meridians. A negative TEC disturbance was detected during the recovery phase at all observation points.

To sum up, the following common features were revealed. During the recovery phases of the weak and moderate storms (no. 1,2) TEC reached its maximum globally. Though there are some similar features found during each phase, in general the intense storms, storms no. 3 and 4, provoked rather complex TEC responses without dependence on the phase. During the recovery phases of the most intense storms, storms no. 5 and 6 , negative TEC bays were observed. These results are confirmed with average TEC behavior in Fig. 5. It should be mentioned that though some similarities in ionosphere variations during the particular phases of storms were revealed, the whole picture is rather complex.

\subsection{Data of GOES-13 satellite}

To complement the analysis of Fig. 5 and for better understanding of phenomena, the results of measurements by the GOES satellite were included in this study. Its orbit in the near-Earth space is at the altitude of $35800 \mathrm{~km}$, which is in the Earth's magnetosphere. Among the measurements performed by the satellite were the intensity of X-rays, protons with energies from $>1$ to $>100 \mathrm{MeV}$ and electrons with energies from $>0.8$ to $>4 \mathrm{MeV}$.

GOES data were studied during the periods of all six geomagnetic storms (Fig. 1). The particle flows of protons and electrons were recorded for all considered storms. However, for storms no. 1-4 (Fig. 1, Table 1) the intensity of these flows did not differ significantly from their undisturbed rate. Rather high levels of particle flows were only observed for storms no. 5 and 6. Even for Dst values of order of $-150 \mathrm{nT}$ 

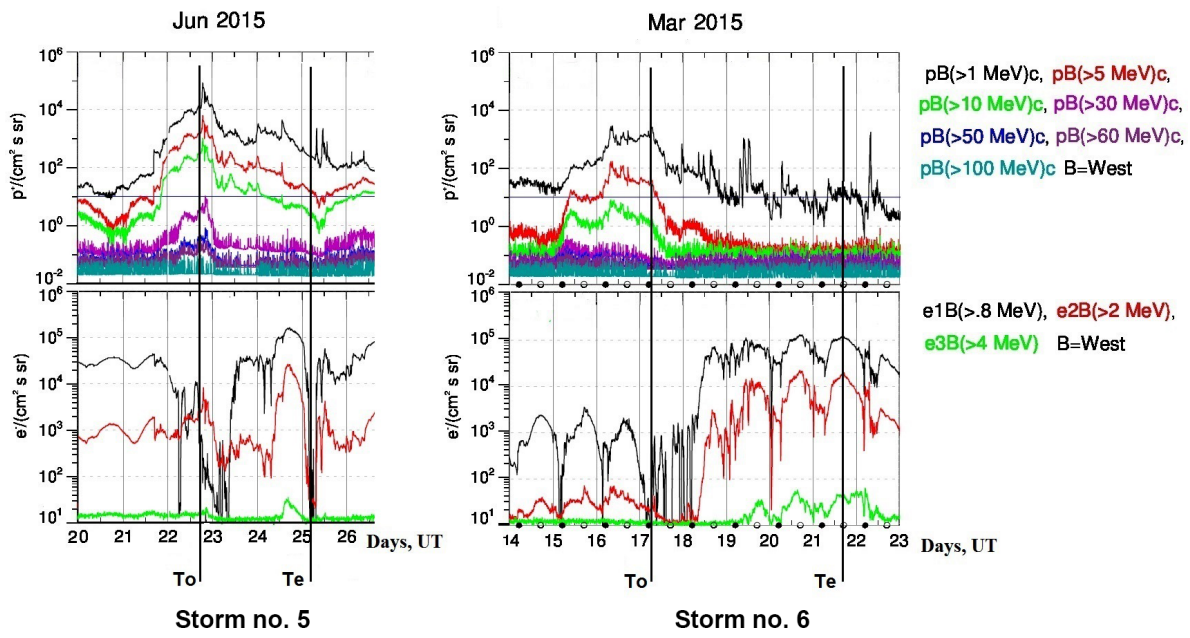

Figure 7. GOES satellite data for storms no. 5 and 6; p: protons, e: electrons. The particle energy is labeled by different colors. The beginning (To) and the end of the storm (Te) are marked by vertical lines.

(storm no. 4) the flow level was rather low, and only for Dst lower than $-200 \mathrm{nT}$ was it significant (intense storms, storms no. 5 and 6, with Dst values of $-204 \mathrm{nT}$ and $-223 \mathrm{nT}$, respectively). Thus, it was impractical to consider satellite data for the first four storms no. 1-4. Figure 7 shows the flows variations for storms no. 5 and 6 . The moments of storm beginnings (To) and storm ends (Te) are labeled with vertical lines for both storms. Figure 1 shows that the amplitudes and the shapes of Dst curves were close for both disturbances. It was of interest to compare the satellite measurements of high-energy particles - protons and electrons. Protons variations (p) are plotted in the upper half of the plots of Fig. 7, and electrons variations (e) in the lower parts. The beginnings of the two storms were approximately at the moment of maximal proton radiation and the beginning of minimal electron flows. Then, the decrease of proton flow occurred in the interval To-Te, but electron flows increased from their minimal to maximal values during the same time. In general, the proton and electron flows during magnetic storms are probably not directly connected with electron density in the ionosphere (Afraimovich and Perevalova, 2006). However, it is possible implicitly. The increase in $\delta$ TECav values (Fig. 5) at the beginning of the storm was probably related to the maximum of proton rates. The decrease in electron flux coincided with $\delta$ TECav decrease. Further, the drastic growth of electron flux intensity took place leading to $\delta$ TECav growth in Fig. 5. In particular, for storm no. 5 (23 June 2015) Fig. 5 illustrates $\delta$ TECav bursts before 23 June, then a decrease to the minimum around 24 June and then again an increase between 24 and 25 June. A similar picture was observed during storm no. 6 (17 March 2015): the maximal intensity of the proton flux was accompanied with a small $\delta$ TECav increase (not significant in this case but existing) near the storm beginning (Fig. 5f), and then the decrease of the flux took place. During 17-18 March the electron flux minimum was ob- served and then its increase. Thus, the character of $\delta$ TECav behavior for two storms in some way is proved by satellite data of energetic protons and electrons.

\subsection{Similarities and differences of $\delta$ TEC response along different meridians during the storms}

We estimated a degree of correlation between $\delta$ TECav along different meridians for each storm during the disturbed periods. This interval was different for each storm. Thus, $16 \delta$ TECav values were found within To-Te during storm no. 1, 23 during storm no. 2, 25 during storm no. 3, 49 during storm no. 4, 33 during storm no. 5 and 58 during storm no. 6 . The distances in degrees between the meridians are the following: American-Euro-African (AmE) $115^{\circ}$, Euro-African-Asian-Australian (E-A) $100^{\circ}$ and Asian-Australian-American (A-Am) $145^{\circ}$. The shortest distance is $\mathrm{E}-\mathrm{A}$ and the largest is $\mathrm{A}-\mathrm{Am}$. Table 2 shows values of correlation coefficient $(R)$ calculated between $\delta$ TEC values along different meridians: (1) averaged along the whole meridian (bold type), (2) averaged along the meridian in the Northern Hemisphere (normal type) and (3) averaged along the meridian in the Southern Hemisphere (italic type).

\subsection{1 $\delta$ TEC averaged along the whole meridians}

Table 2 illustrates the following features for averaging along the whole meridian (bold type).

- A rather high degree of correlation $(R>0.5)$ took place between the $\delta$ TEC variations during storms no. 1-5 for all meridians except two values, $R=0.148$ and $R=$ 0.430 , between Asian-Australian and American meridians. This is explained by the time shift of the $\delta$ TEC peak along the American meridian as shown in Fig. 5c and d. We associate low correlations during storm no. 6 
Table 2. Correlation coefficients between $\delta$ TEC along the three meridians.

\begin{tabular}{|c|c|c|c|c|}
\hline No. & Date of storm & $\begin{array}{r}\text { American-Euro-African } \\
\text { (Am-E) }\end{array}$ & $\begin{array}{r}\text { Euro-African-Asian-Australian } \\
\qquad(\mathrm{E}-\mathrm{A})\end{array}$ & $\begin{array}{r}\text { Asian-Australian-American } \\
\text { (A-Am) }\end{array}$ \\
\hline \multirow{3}{*}{1} & \multirow{3}{*}{14 Dec 2015} & 0.884 & 0.815 & 0.744 \\
\hline & & 0.745 & 0.857 & 0.621 \\
\hline & & 0.561 & 0.640 & 0.744 \\
\hline \multirow{3}{*}{2} & \multirow{3}{*}{6 Mar 2016} & 0.737 & 0.689 & 0.791 \\
\hline & & 0.746 & 0.298 & 0.577 \\
\hline & & 0.635 & 0.673 & 0.758 \\
\hline \multirow{3}{*}{3} & \multirow{3}{*}{31 Dec 2015} & 0.644 & 0.791 & 0.148 \\
\hline & & 0.685 & 0.738 & 0.574 \\
\hline & & 0.394 & 0.808 & 0.012 \\
\hline \multirow{3}{*}{4} & \multirow{3}{*}{20 Dec 2015} & 0.522 & 0.615 & 0.430 \\
\hline & & 0.556 & 0.499 & 0.729 \\
\hline & & 0.239 & 0.508 & 0.128 \\
\hline \multirow{3}{*}{5} & \multirow{3}{*}{23 Jun 2015} & 0.672 & 0.832 & 0.724 \\
\hline & & 0.449 & 0.158 & 0.467 \\
\hline & & 0.717 & 0.854 & 0.716 \\
\hline \multirow{3}{*}{6} & \multirow{3}{*}{17 Mar 2015} & 0.362 & 0.463 & 0.004 \\
\hline & & 0.279 & 0.172 & 0.332 \\
\hline & & 0.071 & 0.509 & -0.086 \\
\hline
\end{tabular}

with the complexness of local phenomena because of the high intensity of the storm (including no correlation in the case $\mathrm{A}-\mathrm{Am})$.

- The highest $R$ values (if comparing three pairs of meridians) were found between European and AsianAustralian sectors in five cases of six.

- The highest $R$ values between all three meridians $(R>$ $0.5)$ were during the weakest storm, storm no. 1 . This corresponds to the physics of phenomena. Perturbations and irregularities in the ionosphere are more pronounced during intense disturbances than during moderate or weak disturbances. During the weak storm the ionosphere structure is not significantly changed and its global stability is retained.

- The lowest $R$ values (in bold) took place between Asian-Australian and American sectors when compared to other two pairs, at least for five storms of six. It is probably explained by the fact that the distance between the American and Asian meridians is the largest $\left(145^{\circ}\right)$. Another possible cause is that storm beginnings were observed in the opposite local time zones (day or night local hours) for these two meridians during all storms under analysis.

- The not-evident, mixed dependence of $R$ on the intensity of magnetic disturbance is common for all three meridians. For example, the comparison of $R$ for storms no. 1-4 shows that $R$ values are decreasing from values of $R=0.884(\mathrm{Am}-\mathrm{E}), R=0.815(\mathrm{E}-\mathrm{A})$ and $R=0.744(\mathrm{~A}-\mathrm{Am})$ to values of $R=0.522(\mathrm{Am}-\mathrm{E})$, $R=0.615$ (E-A) and $R=0.430$ (A-Am) during disturbances. This is in accordance with the physics of phenomena. However, the transition from storm no. 4 to storm no. 6 shows an inverse dependence, i.e., some growth of $R$ instead of its decrease for storm no. 5. Nevertheless, in general, $R$ behavior in dependence on the intensity of the magnetic disturbance (transition from storm no. 1 to storm no. 6) showed a decrease of $R$ values, which is to be expected. The lowest $R$ values were for the most intense storm.

\subsection{2 $\quad \delta$ TEC averaged along meridians in each hemisphere}

It is known that TEC behavior has a seasonal dependence (Afraimovich and Perevalova, 2006). As the seasons are opposites in two hemispheres, the effects in the north and south can be different. In general, it is revealed that the intense bursts of $\delta$ TEC took place at subpolar latitudes of both hemispheres. To compare northern and southern data, first the averaging of $\delta$ TEC was performed along each meridian separately in each hemisphere: between the latitudes 60 and $10^{\circ} \mathrm{N}$ (northern) and then between the latitudes 10 and $60^{\circ} \mathrm{S}$ (southern). The middle and lower panels of Fig. 6 serve as an example. Though the averaging along the meridian implies only qualitative, not quantitative estimate of deviations, it was of interest to analyze the effects separately. Ta- 
ble 2 presents the results of $R$ calculations made separately for Northern (normal type) and Southern (italic type) hemispheres.

- Storms no. 5 and 6 are close in terms of the intensities of their disturbance, but different in terms of the season of occurrence (summer/winter and winter/summer). $R<0.5$ in the Northern Hemisphere (summer) and $R>0.5$ in the Southern Hemisphere (winter) were observed along all three meridians during storm no. 5. For storm no. 6 the opposite picture is seen. $R<0.5$ in both hemispheres and there was no correlation in cases Am$\mathrm{E}$ and $\mathrm{A}-\mathrm{Am}$. But in cases that there was a correlation, $R$ was lower in the Southern Hemisphere (summer) than in the Northern Hemisphere (winter) when the correlation was detected (E-A). It may be related to the seasonal effect, but more statistics are needed to conclude.

- Comparison of $R$ for the Southern and the Northern Hemisphere shows a rather high degree of correlation in both hemispheres simultaneously $(R>0.5)$ only for the weakest storm, storm no. 1 . For other storms the number of cases when $R<0.5$ increases with the disturbance intensity are as follows: one case for storm no. 2, two cases for storm no. 3 , three cases for storms no. 4 and 5 and five cases for storm no. 6 . In other words, the difference in $R$ values in the Northern and the Southern Hemisphere grows with the increase of magnetic activity. It results that seasonal effect has impact here.

- The correlation coefficients, $R$, calculated along a whole meridian (bold values) are close to maximal $R$ values of only the Northern or only the Southern Hemisphere.

\subsection{3 $\delta$ TEC along the three meridians in each latitude sector (without averaging)}

We briefly mention that $R$ behavior was also studied without averaging (at each latitude separately). The results confirmed the last conclusion of Sect. 3.3.1: the lower the intensity of magnetic storm, the more the number of moderate and strong correlations between $\delta$ TEC at different latitudes $(R>0.45)$. Mild and weak correlations prevailed with the growth of the intensity of storms. The number of negative correlations also increased with the storm intensity growth. For instance, 11 such cases of a total 39 were found for superstorm no. 6 .

For storm no. 5 (23 June 2015) $R$ behavior was found to be similar for all three pairs of meridians: $R$ was positive within the latitudes \pm 60 and $\pm 10^{\circ}$ (in both hemispheres) and $R$ was rather low or negative within the interval from $10^{\circ} \mathrm{N}$ to $10^{\circ} \mathrm{S}$. Consequently, the ionosphere processes in the equatorial zone were due to different physical causes along the three meridians.

\section{Conclusions}

The features of behavior of the total electron content deviation from its 27-day median value were studied during six geomagnetic storms of different intensity along three meridians: American, Euro-African and Asian-Australian. The storms were chosen within a short period of time (1 year). Though six storms is not a large set of statistics, some features of TEC variations during these particular events were obtained.

1. During the majority of considered storms at all meridians the maximum of $\delta$ TEC bursts occurred almost simultaneously at high latitudes in the north and south and at the equator, provided that the consideration was along each meridian separately. The analysis of TEC response to each separate storm phase showed a rather complex picture. The following common features were revealed. During the recovery phases of the weak and moderate storms TEC reached its maximum globally. During the recovery phases of the most intense storms (Dst $<-200 \mathrm{nT}$ ) negative TEC bays were observed. During the other two intense storms (Dst $>-200 \mathrm{nT}$ ), no clear dependence of TEC responses on the storm phases was found.

2. It was revealed that the beginning of TEC disturbance during the superstorm 17 March 2015 did not qualitatively differ from the beginning of other storms: an increase of $\delta$ TECav was followed by its decrease. The transition from a weak storm to a superstorm (the increase of magnetic activity) almost does not influence the intensity of $\delta$ TECav maximum.

3. The seasonal effect (general dominance of negative/positive phase in summer/winter) was mostly observed along the Asian-Australian meridian. No seasonal effect was recorded over the American sector. Our results prove the possibility of the seasonal effect penetrating into the opposite hemisphere (in our case from the Southern to the Northern Hemisphere). We did not find dependence of such penetrations on the season itself or on the hemisphere.

4. The character of $\delta$ TEC for the most intense storms under analysis (23 June 2015 with Dst $t_{\min }=-204 \mathrm{nT}$ and 17 March 2015 with Dst $_{\min }=-223 \mathrm{nT}$ ) is rather similar despite the opposite seasons of occurrence of storms and in some way is confirmed by GOES satellite data of energetic proton and electron fluxes.

5. The analysis of correlation coefficients between average $\delta$ TEC variations along the three meridians during each storm showed the following.

- The degree of correlation between $\delta$ TEC values averaged along a whole meridian was rather high 
$(R>0.5)$ along all three meridians. This result is new. There are five exceptions of 18 cases from Table 2: (a) $R=0.148$ and $R=0.430$, both found between Asian-Australian and American meridians, and (b) low $R$ during the most intense storm, storm no. 6. Issue (b) is associated with the complexity of phenomena during the most intense storm.

- The highest coefficients of correlation between $\delta$ TEC values averaged along a whole meridian (all three $R>0.5$ ) took place during the weakest storm. This is due to the fact that during the weak storm the ionosphere structure is not significantly changed and its global stability is retained. Comparison of $R$ between $\delta$ TEC averaged separately in the Northern and the Southern Hemisphere also showed that a high degree of correlation for both hemispheres $R>0.5$ only took place for the weak storm. The difference between hemispheres increased with the increase of magnetic activity, which probably again is explained by seasonal effect.

- The lowest coefficients of correlation (through all the storms in general) were found between AsianAustralian and American meridians. The reasons may include the largest distance between these meridians and discordance in local time of storm occurrence.

- The not-evident, mixed dependence of $R$ on the intensity of magnetic disturbance is common for all three meridians. Nonetheless, the transition from the weak to the most intense storm shows the decrease of correlation till its absence or even negative correlations. This result is new. It is confirmed by correlation coefficients between both average $\delta$ TEC and $\delta$ TEC at each separate latitude. In general, the more the intensity of magnetic disturbance, the lower the correlation rates between $\delta$ TEC variations along the three meridians.

- Calculation of $R$ separately for two hemispheres allowed us to reveal that the most intense $\delta$ TEC bursts took place at subpolar latitudes of both hemispheres. For the two storms on 23 June 2015 and 17 March 2015, close in intensity but different in season, the following is revealed. For the summer storm of 23 June $2015 R$ values were less than 0.5 in the Northern Hemisphere and more than 0.5 in the Southern Hemisphere between all three meridians. For the storm of 17 March $2015 R$ values were less than 0.5 , but in general, the picture was the opposite: correlation coefficients were lower in the Southern Hemisphere and higher in the Northern Hemisphere (when correlation was detected). The seasonal effect probably plays a main role here.
- For the storm of 23 June 2015, $R$ between $\delta$ TEC at each latitude for all three pairs of meridians was positive within the latitudes \pm 60 and $\pm 10^{\circ}$ (in both hemispheres) and was rather low or negative within the interval $10^{\circ} \mathrm{N}-10^{\circ} \mathrm{S}$. Consequently, the ionosphere processes in the equatorial zone were the subject of different physical causes along the three meridians.

Data availability. TEC data in the IONEX format are available from International GNSS Service by following the link ftp://cddis. gsfc.nasa.gov/pub/gps/products/ionex (last access: 5 January 2018). GOES satellites data were obtained from the NOAA's National Centers for Environmental Information by following the link https: //satdat.ngdc.noaa.gov/sem/goes (last access: 5 January 2018). Dst and SYM-H indices data are available from Data Analysis Center for Geomagnetism and Space Magnetism by following the link http://wdc.kugi.kyoto-u.ac.jp (last access: 5 January 2018).

Competing interests. The authors declare that they have no conflict of interest.

Acknowledgements. The work was supported by grant no. 18-0500343 from the Russian Foundation for Basic Research. The work of Olga A. Maltseva was supported by a grant under the state task N3.9696.2017/8.9 from the Ministry of Education and Science of Russia. SCiESMEX is partially funded by CONACyTAEM grant 2014-01-247722, CONACyT LN 269195 and DGAPAPAPIIT grant IN106916. Maria A. Sergeeva acknowledges the partial funding by the Sectoral Fund for Research, Technological Development and Innovation in Space Activities, CONACYT-AEM (project 292700, 28/05/2018).

The authors express their gratitude to the services of IGS for the opportunity to use IONEX data via the internet. We also thank NOAA's National Centers for Environmental Information for the opportunity to use GOES satellite data. Dst and SYM-H indices data were obtained from the Data Analysis Center for Geomagnetism and Space Magnetism, Kyoto University, Japan.

The authors would like to thank the anonymous reviewers for their contributing comments.

The topical editor, Ana G. Elias, thanks two anonymous referees for help in evaluating this paper.

\section{References}

Afraimovich, E. L. and Perevalova, N. P.: GPS-monitoring of Earth upper atmosphere. Irkutsk, Russian Academy of Sciences, Siberian Branch, 460 p., ISBN 5-98277-033-7, 2006.

Astafyeva, E., Zakharenkova, I., and Forster, M.: Ionospheric response to the 2015 St. Patrick's Day storm: a global multiinstrumental overview, J. Geophys. Res.-Space Phys., 120, 9023-9037, https://doi.org/10.1002/2015JA021629, 2015.

Astafyeva, E., Zakharenkova, I., and Alken, P.: Prompt penetration electric fields and the extreme topside ionospheric re- 
sponse to the June 22-23, 2015 geomagnetic storm as seen by the Swarm constellation, Earth Planets Space, 68, 152, https://doi.org/10.1186/s40623-016-0526-x, 2016.

Astafyeva, E., Zakharenkova, I., Huba, J. D., Doornbos, E., and van den IJssel, J.: Global Ionospheric and Thermospheric Effects of the June 2015 Geomagnetic Disturbances: Multi-Instrumental Observations and Modeling, J. Geophys. Res.-Space Phys., 122, 11, https://doi.org/10.1002/2017JA024174, 2017.

Bhuyan, P. K., Chamua, M., Bhuyan, K., Subrahmanyam, P., and Garg, S. C.: Diurnal, seasonal and latitudinal variation of electron density in the topside F-region of the Indian zone ionosphere at solar minimum and comparison with the IRI, J. Atmos. Sol.-Terr. Phys., 65, 359-368, https://doi.org/10.1016/S13646826(02)00294-8, 2003.

Blagoveshchensky, D. V.: Short waves in the anomalous radio channels, LAP LAMBERT Academic Publishing GmbH \& Co. KG, Saarbrücken, Germany, 422 p., 2011.

Cander, L. R. and Ciraolo, L.: Ionospheric Total Electron Content and Critical Frequencies over Europe at Solar Minimum, Acta Geophys., 58, 468-490, https://doi.org/10.2478/s11600009-0061-2, 2010.

Chashei, I. V., Tyul'bashev, S. A., Shishov, V. I., and Subaev, I. A.: Interplanetary and ionosphere scintillation produced by ICME, Space Weather, 14, 682-688, https://doi.org/10.1002/2016SW001455, 2016.

Chen, Y. N. and Xu, J. S.: Longitudinal structure of plasma density and its variations with season, solar activity and dip in the topside ionosphere, Chinese J. Geophys.-Ch., 58, 1843-1852, https://doi.org/10.6038/cjg20150601, 2015.

Data Analysis Center for Geomagnetism and Space Magnetism: Dst and SYM-H indices data, available at: http://wdc.kugi.kyoto-u. ac.jp, last access: 5 January 2018.

Davies, K. and Hartmann, G. K.: Studying the ionosphere with the Global Positioning System, Radio Sci., 32, 1695-1703, https://doi.org/10.1029/97RS00451, 1997.

Dmitriev, A. V., Huang, C.-M., Brahmanandam, P. S., Chang, L. C., Chen, K.-T., and Tsai, L.-C.: Longitudinal variations of positive dayside ionospheric storms related to recurrent geomagnetic storms, J. Geophys. Res.-Space Phys., 118, 6806-6822, https://doi.org/10.1002/jgra.50575, 2013.

Gonzalez, W. D., Joselyn, J. A., Kamide, D., Kroehl, H. W., Rostoker, G., Tsurutani, B. T., and Vasyliunas, P.: What is a geomagnetic storm?, J. Geophys. Res., 99, 5771-5792, 1994.

Gulyaeva, T. L. and Stanislawska, I.: Derivation of a planetary ionospheric storm index, Ann. Geophys., 26, 2645-2648, https://doi.org/10.5194/angeo-26-2645-2008, 2008.

Hernandez-Pajares, M., Juan, J. M., Orus, R., Garcia-Rigo, A., Feltens, J., Komjathy, A., Schaer, S. C., and Krankowski, A.: The IGS VTEC maps: a reliable source of ionospheric information since 1998, J. Geod., 83, 263-275, https://doi.org/10.1007/s00190-008-0266-1, 2009.

International GNSS Service: TEC data, available at: ftp://cddis.gsfc. nasa.gov/pub/gps/products/ionex, last access: 5 January 2018.

Jakowski, N., Stankov, S. M., Schlueter, S., and Klaehn, D.: On developing a new ionospheric perturbation index for space weather operations, Adv. Space Res., 38, 2596-2600, 2006.

Kil, H., Paxton, L. J., Pi, X., Hairston, M. R., and Zhang, Y.: Case study of the 15 July 2000 magnetic storm effects on the ionosphere-driver of the positive ionospheric storm in the winter hemisphere, J. Geophys. Res., 108, 1391, https://doi.org/10.1029/2002JA009782, 2003.

Klimenko, M. V., Klimenko, V. V., Bessarab, F. S., Zakharenkova, I. E., Vesnin, A. M., Ratovsky, K. G., Galkin, I. A., Chernyak, I. V., Yasyukevich, Y. V., Koren'kova, N. A., and Kotova, D. S.: Diurnal and Longitudinal Variations in the Earth's Ionosphere in the Period of Solstice in Conditions of a Deep Minimum of Solar Activity, Cosmic Res.+, 54, 8-19, https://doi.org/10.1134/S001095251601010X, 2016 a.

Klimenko, M. V., Klimenko, V. V., Zakharenkova, I. E., Vesnin, A. M., Cherniak, I. V., and Galkin, I. A.: Longitudinal variation in the ionosphere-plasmasphere system at the minimum of solar and geomagnetic activity: Investigation of temporal and latitudinal dependences, Radio Sci., 51, 1864-1875, https://doi.org/10.1002/2015RS005900, 2016b.

Komjathy, A.: Global ionospheric total electron content mapping using the Global Positioning System, PhD Dissertation, Department of Geodesy and Geomatics Engineering Technical Report No. 188, University of New Brunswick, Fredericton, New Brunswick, Canada, 1997.

Liu, W., Xu, L., Xiong, C., and Xu, J.: The ionospheric storms in the American sector and their longitudinal dependence at the northern middle latitudes, Adv. Space Res., 59, 603-613, https://doi.org/10.1016/j.asr.2016.10.032, 2017.

Mansilla, G. A.: Moderate geomagnetic storms and their ionospheric e?ects at middle and low latitudes, Adv. Space Res., 48, 478-487, https://doi.org/10.1016/j.asr.2011.03.034, 2011.

NOAA's National Centers for Environmental Information: GOES satellites data, available at: https://satdat.ngdc.noaa.gov/sem/ goes, last access: 5 January 2018

Nogueira, P. A. B., Abdu, M. A., Souza, J. R., Bailey, G. J., Batista, I. S., Shume, E. B., and Denardini, C. M.: Longitudinal variation in Global Navigation Satellite Systems TEC and topside ion density over South American sector associated with the four-peaked wave structures, J. Geophys. Res.-Space Phys., 118, 7940-7953, https://doi.org/10.1002/2013JA019266, 2013.

Panda, S. K., Gedam, S., and Rajaram, G.: Study of Ionospheric TEC from GPS observations and comparisons with IRI and SPIM model predictions in the low latitude anomaly Indian subcontinental region, Adv. Space Res., 55, 1948-1964, https://doi.org/10.1016/j.asr.2014.09.004, 2015.

Polekh, N. M., Zolotukhina, N. A., Romanova, E. B., Ponomarchuk, S. N., Kurkin, V. I., and Podlesnyi, A. V.: Ionospheric effects of magnetospheric and thermospheric disturbances on March 17-19, 2015, Geomagn. Aeronomy+, 56, 557571, https://doi.org/10.1134/S0016793216040174, 2016.

Rajesh, P. K., Liu, J. Y., Balan, N., Lin, C. H., Sun, Y. Y., and Pulinets, S. A.: Morphology of midlatitude electron density enhancement using total electron content measurements, J. Geophys. Res.-Space Phys., 1503-1507, https://doi.org/10.1002/2015JA022251, 2016.

Schaer, S., Beutler, G., Mervart, L., Rothacher, M., and Wild, U.: Global and regional ionosphere models using the GPS double difference phase observable, Proceedings of the IGS Workshop, Potsdam, Germany, 15-17 May 1995, 1-16, 1995.

Wanliss, J. A. and Showalter, K. M.: High-resolution global storm index: Dst versus SYM-H, J. Geophys. Res., 111, A02202, https://doi.org/10.1029/2005JA011034, 2006. 